\title{
The Challenge of Varying Perceptions of Sexual Harassment: An International Study
}

\author{
Anne M. Fiedler \\ Barry University \\ R. Ivan Blanco \\ Texas State University - San Marcos
}

\begin{abstract}
Globalization has put increasing pressure on organizations to better prepare employees facing cross cultural problems regarding HR issues. This study examines the subject of varied interpretations of sexual harassment in the global arena. A model is suggested based on legal and cultural differences, and data is presented regarding the perceptions of various types of sexual harassment of residents of three countries. Differences in the perceptions based on gender are also examined. Significant differences in perceptions of sexual harassment were found according to country of residence, types of harassment, and gender scripts.
\end{abstract}

\section{Introduction}

The new global business order demands a complete revision of the business practices corporations have relied on for many decades. Companies have responded to the global market by adapting, adjusting, and reinventing their production processes, their product designs, their marketing and sales strategies, and other operational functions. But the response in terms of the personnel supporting activities has not been as clearly vigorously pursued. There has been some interest in the identification of the effects of the global market on human resource practices. However, most of the efforts do not seem to fill the need organizations have today in the area of international human resources. For instance, it is common to read about the number of managers and other employees who return to their home country, after failing to adapt to the culture of the foreign country assignment. In addition to this, there is a very clear indication that most American managers lack the necessary skills to deal effectively with Americans from various ethnic backgrounds (Barnum, 1990). No much has been done to correct this problem and other similar ones. What is probably needed is a more systematic set of practices to help managers and employees to deal with the new HR challenges of the global market. The consequences of not preparing employees to deal effectively with global diversity could be very costly.

Sexual harassment is clearly an example of the challenges faced by the Human Resource function in the new global market. It is probably the one episode that, regardless of how it is defined, is found in almost all cultures. It is also a behavior very pervasive to organizations. It is the one that varies the most from culture to culture in terms of intensity and recognition. The definition of what constitutes sexual harassment varies between different countries and cultures. However, we can speculate that 
modern information technologies allow people to learn about how sexual harassment is defined and handled in the U.S.

Many countries outside of the United States have claimed that they have little sexual harassment compared to the United States. However, this assumption is often based on the number of filings within that country. This can give a much distorted picture because the citizens of these foreign countries may not file charges due to differences in the laws and differences in the cultures, including accepted differences in the power structures between men and women in the work place.

In fact, while surveys in the U.S. have shown that approximately $40 \%$ of American women believe that they have been sexually harassed during their working life (Englander, 1992), European polls find that depending on the country, 20 to 70 percent of working European women believe that they have been sexually harassed. Other studies in the EU report that approximately 50 percent of the women and 10 percent of the men in the EU say that they have experienced some type of sexual harassment. However, an EU official commented that sexual harassment was reported more frequently in the northern European countries because there the phenomenon is more widely recognized and reported (Rueters, 2002). The head of the Women's Institute in Spain stated that the problem of sexual harassment has always existed, but that women in Spain are only beginning to realize that it is an offense (Riding, 1992)

In this paper, the authors develop a model based on various factors such as culture, laws, and gender that may impact perceptions of what constitutes sexual harassment. Then, using data gathered from subjects in three countries that are very close geographically, but have very different cultures and laws, the authors compare perceptions of sexual harassment. This awareness will be useful in giving managers and human resource executives an insight into the way people from different cultures view the same issues. It will helpful in understanding the motives and behaviors of employees and contacts from other countries. This may assist the trainers in developing training programs for employees and managers that will be dealing with people from these other cultures.

\section{Determinants of Perceptions of Sexual Harassment}

This section of the paper will attempt to give some perspective on three major forces that impact the prevalence and perception of sexual harassment in the international business community. The first section will discuss the impact of gender scripts on perceptions of sexual harassment. The second section will discuss the cultural aspects in countries that impact the effectiveness of these regulations. The third section discusses some of the laws regulating sexual harassment in the work place in various countries. 


\section{$\underline{\text { Internal Scripts }}$}

Everyone carries internal scripts that influence how we perceive events in the world around us. Many behaviors in the work place are mindless performances based on these internal scripts that help an employee to make sense of a situation and formulate appropriate behavior (Ashforth \& Fried, 1988). These scripts often lead to "business justifications" for racism and other types of prejudicial behavior (Brief \& Hayes, 1997).

\section{Gender}

Determining whether or not a person has been sexually harassed is very subjective. Research has shown that a person's gender impacts his or her perceptions of sexual harassment (Baird, Bensko, Bell, Viney, \& Woody, 1995; Gutek, Morasch \& Cohen, 1983, Padgitt \& Padgitt, 1986). Women are often more sensitive to what constitutes sexual harassment than men, and they often judge the same behavior to be more serious (Dietz-Uhler \& Murrell, 1992; Popovich, Gehlauf, Jolton, Somer, \& Godinho, 1992).

The U.S. courts have even acknowledged that gender differences exist in the interpretation of which behaviors constitute sexual harassment. This has been demonstrated by the shift in the courts from using the "reasonable person" standard when judging sexual harassment cases to the use of the "reasonable woman" standard (Thacker \& Gohmann, 1993). In a study by Baird, et.al. (1995) men and women were given scenarios where sometimes a man was the perpetrator and sometimes a woman was the perpetrator. The women participating in the study tended to be more sensitive to the hostile environment scenarios than the men, regardless of the gender of the perpetrator.

\section{$\underline{\text { Culture }}$}

When trying to understand sexual harassment in the international business environment, understanding the legal constraints may not be enough. It may be more important is to understand the interpretation of the law based on the cultural environment of the society in which the law is being enforced.

\section{Application of Hofstede's Typology}

Vitell, Nwachakwu, \& Barnes (1993) applied Hofstede's cultural typology in a model designed to help understand different perceptions of ethical decision making across countries. They proposed that the degree that various countries ranked high or low on Hofstede's four cultural dimensions (power distance, individualism, masculinity, and uncertainty avoidance) would impact perceptions of ethical business practices. The application of Hofstede's four topologies would also help clarify the effect of culture on perceptions of sexual harassment. For example, countries that rank high on the masculinity scale, such as the Latin American countries, place more value on "tough" (hard) values such as power, success, money, assertiveness and competition, and less emphasis on relationships, feelings, and the preservation of human dignity than the 
countries that rank high on femininity such as the northern European countries.

Therefore, in these masculine cultures sexual harassment would be more likely to be condoned.

Employees in countries low on individualism would tend to be more susceptible to group and intra-organizational influence than employees with high levels of individualism. In collectivist cultures, such as Japan and Mexico, workers are not only more likely to take on the norms of the groups, but also they are likely to consider other employees as more important stakeholders than themselves. There would be a tendency to maintain group harmony. It would then hold that employees in collectivist cultures would be less likely to perceive actions as being sexually harassing if the group did not perceive it to be sexual harassment, and even if they did believe that they were being sexually harassed they may be less likely to report it for fear of disrupting the cohesiveness of the group.

Business practitioners in countries with high power distance are more likely to accept inequality in power and authority (Hofstede, 1983). Vital et. al. (1993) proposed that business practitioners in countries with high power distance would be more likely to take their ethical cues from their superiors. We assert that in countries with high power distance, such as Japan, employees would be more likely to define sexual harassment based on the interpretation of sexual harassment by their supervisor who is usually male; whereas in countries such as the U.S. that have low power distance, employees are more likely to develop their own decontological norms.

Also members of organizations in countries that rank high on the uncertainty avoidance scale would tend to show great concern for security in life and the need to maintain consensus (Hofstede, 1991). Employees seem to be less ambitious and managers are more task oriented in these organizations as well (Hofstede, 1984). Employees would rely more on the structure and rules dictated by the organization. We argue that employees in these countries would be less inclined to jeopardize their jobs and to break to the "harmony" in their organizations with complaints about others' behaviors on the job. They would also understand that managers would not be as concerned with any problem not directly related to the work itself. Thus it is very likely that some manifestations that could be considered as sexual harassment would be neglected as unimportant or irrelevant to the organization.

\section{Brief Overview of Sexual Harassment Issues in Selected Areas of the World}

The following section briefly discusses some examples of the impact of local culture in various countries when trying to develop an understanding of the sexual harassment issue. 


\section{$\underline{\text { The European Union }}$}

Even though the laws seem quite similar at first reading, the way the courts and the general populace interpret what constitutes sexual harassment and what is covered by these laws is greatly influenced by the culture of the given nation. Therefore, countries that have very similar laws governing an issue such as sexual harassment may still have very different approaches in the interpretation and enforcement of those laws.

This is evident in the EU and the U.S. where although the laws regarding this issue may seem very similar, there is an underlying difference in the interpretation of the meaning. Michael Rubenstein, the author of the EU's Report and Code of Practice on Sexual Harassment, believes the difference is based on the ways the two societies view ethics (BNA, 1994). Americans tend to see ethics in terms of rules and regulations that carry with them rewards and sanctions. U.S. companies often give their workers extensive checklists, policies, or guidelines to tell them what is right and wrong. Europeans, however, overlook such checklists and base their codes of behavior on ethical traditions that have been passed down through church and family (Vogel, 1993).

The U.S. model gives guidelines to American employers and employees that specifically tell them what constitutes harassment and what does not, whereas according to Rubenstein, the European model gives each member of the organization or even society "the right to determine what is offensive to them." Law Professor and former Fulbright Scholar in European Affairs, Anita Bernstein, who studied the differences between American sexual harassment laws and those of the European Community based on cultural differences found that "in Europe there's a less adversarial approach, more involving negotiation" (Duncan, 1993).

It is important to recognize that differences not only exist between the U.S. and the European Community, but between European countries. There are some differences between European countries because of their social traditions, the church's level of influence on society, and other cultural factors, which vary from country to country. For instance, one could expect that the level of respect between people (including issues regarding sexual harassment) might be more defined by family and church traditions in Spain than in Germany or the U.K. In the later countries the legal side may have a stronger influence in defining sexual harassment issues and related actions. Behavior in organizations may differ from country to country. Southern European countries, with their more Latin based cultures, would tend to show higher scores in the uncertainty avoidance index than their partners in northern Europe (Hofstede, 1991). This difference could also imply that they would react differently to sexual harassment. An employee in Spain may not complain about the behavior of a supervisors or coworker because it might be seen as a disruption of the organizational harmony, an important condition in countries ranking high in the uncertainty avoidance index. 


\section{Developing Nations}

Mexico suffers from a problem which is common to most Latin-American cultures: Machismo, which often makes the environment hostile to the female workers, but is so embedded in the culture that it is an accepted way of life (Grant, 1995). As discussed above, Brazil has sexual harassment laws, violation of which carries fairly heavy fines. However, once again due to the Machismo culture most men do not take the law seriously, and it is rarely enforced. Although Brazil possesses a well organized women's movement in Latin America, the country probably has the worst record in discrimination and abuses against women at work, in the family and other situations.

Most developing countries, in general, and the Latin American nations, in particular, score very high on the uncertainty avoidance index, on collectivism, and masculinity, and also exhibit high levels of power distance. This combination of factors may explain some of the low number of filings in sexual harassment cases. Examining the descriptors offered by Hofstede (1991) under each one of these dimensions, it would be reasonable to surmise that culture has a strong influence in determining what constitutes sexual harassment and how it should be handled in different countries.

\section{Brief Review of the Legal Aspects of Sexual Harassment in Selected Areas of the World}

Sexual harassment has become an important issue in the international legal environment for three reasons. First, the global labor force has shown a significant increase in the participation rate of women to almost 50 percent worldwide (United Nations Statistics Division, 2000). Second, women have been penetrating professions and occupations that were, for the most part, the domain of male workers. Third, there exists a great disparity among laws in various countries dealing with sexual harassment. This section will demonstrate this point by comparing the laws pertaining to sexual harassment in several countries, particularly those that are involved in major trade relationships with the United States and that often send employees across national borders.

\section{The United States}

The issue of sexual harassment has become one of the dominant issues in the American society in general, and in American business in particular. As a result of the interpretations of the laws governing sexual harassment by various Federal and State courts, the definition of what constitutes sexual harassment in the United States is broadening. There is no federal law in the U.S. passed specifically to deal with sexual harassment in the work place. This issue falls under the purview of the antidiscrimination laws.

The Civil Rights Act of 1964 was passed by the American Congress to help eliminate various types of discrimination, such as discrimination passed on gender, race, ethnic background or religion. Title VII of the Civil Right Act of 1964 also created the Equal 
Employment Opportunity Commission to enforce the law and to set up guidelines for "highly recommended practices regarding the law." These guidelines interpret Title VII as inclusive of sexual harassment as a form of gender discrimination. Further, the Supreme Court has interpreted the definition of sexual harassment to include both "quid pro quo" cases and hostile environment cases (Sullivan, 1986).

The Civil Rights Act of 1991 expanded the severity of the results of a sexual harassment case by allowing the addition of punitive damages to the already available compensatory damages. Some State laws, such as those in California, also have provisions for punitive damages, and some companies have been forced to pay several million dollars to victims that were not adequately protected from sexual harassment within their organizations. In recent years, various Federal and State courts in the United States have expanded the definition of sexual harassment to sometimes include women harassing men and same sex harassment. The U.S. has some of the strongest laws in the world dealing with sexual harassment. This may be due to the fact that the U.S. has many more women activist groups pushing for these issues than any other country of the world.

\section{The European Union}

The EU has passed a new law protecting employees from sexual harassment in the work place and holding employers financially liable for cases of misconduct. Under this law, sexual harassment is defined as any form of unwanted... conduct of a sexual nature with the purpose or effect of violating the dignity of a person, in particularly when creating an intimidating, hostile, degrading, humiliating or offensive environment (Rueters, 2002). The impact of this new law is as yet unknown as the EU directive did not come into force until 2005.

\section{Developing Countries}

The disparities are in the law are evident when looking at a comparison of the sexual harassment issue in third world countries verses industrialized nations. Jamaica is unique regarding gender issues when compared to other less developed countries. This is because not only do women make up a significant part of the labor force, but they are more highly represented among the managerial elite. This is because of the high proportion of women who are enrolled in institutions of higher learning while young men are encouraged in agricultural pursuits (Gershenberg, 1994).

In Jamaica, women suffer from economic discrimination and sexual harassment in the workplace. There are no laws in existence that deal with sexual harassment. The Constitution and the 1975 Employment Act accord women full equality, but do not protect them from discrimination. The Bureau of Women's Affairs in the Ministry of Labor oversees programs to ensure the legal rights of women; however, these programs have had limited effect. Informal reports received by the Bureau and through other women's groups suggest that sexual harassment in the workplace is increasing (Tomlinson, 2004). 
In 1996 the Government established a steering committee, charged with creating a Commission on Gender and Social Equity. The committee forwarded its recommendations to Parliament, which accepted them. Parliament; however, there is no legislation that addresses sexual harassment. There are reports of sexual harassment of women by the police, but some observers believe that women often do not report such incidents because there is no legal remedy (Bureau of Democracy, Human Rights, and Labor, 2000a Bureau of Democracy, Human Rights, and Labor, 2000a,).

Some other developing countries have sexual harassment and/or sexual discrimination laws on the books, but the results are not much different. For example, in the Dominican Republic even though there are laws prohibiting sexual discrimination, women have not traditionally shared equal status or opportunity with men. It is believed to be rampant, perpetuated by corruption and organized crime (U.S. Department of State, 1993).

Mexico does have a law prohibiting sexual harassment under the Federal Criminal Code. However, sexual harassment in the workplace was considered widespread by NGO's and women's agencies. Many female victims are reluctant to come forward, and cases are difficult to prove. The problem is two-fold. First, the way the law is written is not supportive of the plaintive. The burden of proof lies heavily on the victim. Second, many women fear that they will be fired if they file charges, and that their employer will make it difficult for them to find another job.

Although the Mexican Constitution guarantees equality between the sexes, neither the authorities nor society in general respect this in practice. The legal treatment of women's rights is uneven. Reports of sexual harassment in the workplace are widespread. The Mexico City Human Rights Commission estimated that at least 80 percent of the women who work in Mexico City have experienced sexual harassment (Bureau of Democracy, Human Rights, and Labor, 2000b).

Mexican women are lucky compared to some of their South American counterparts. Most Latin American countries do not have any laws involving sexual harassment. In fact, rights that women in industrialized countries take for granted are being slowly gained in these male bastions. For example in 1992, Paraguay rescinded legislation giving husbands the right to prevent their wives from holding outside employment. In 1993, Chilean women gained the right to work at night, and Colombia and Venezuela were considering legislation that would give women equal status as workers (National Catholic Reporter, 1994), but nothing concrete has happened to this date.

Brazil is the Latin American country with an organized and most effective women's movement. Brazil's 1988 constitution guarantees equal rights for men and women, and in 1991, a law was passed in Rio outlawing sexual harassment, making it a crime punishable by fines up to $\$ 20,000$. In the most economically and educationally advanced Latin countries, there is considerable progress being made in the reduction of discrimination and abuses against women in the work place. It could be said that this 
progress has been reached without the "militant women's organizations" that are found in the U.S. (Greer, 1994).

\section{Sexual Harassment in the International Environment: A Perceptual Model}

Of course, neither a country's cultural values nor its laws stand alone. They are constantly influencing each other, and thereby, both are being redefined in an on-going process. This is shown in the first part of Figure 1. This model was designed to help to understand perceptions of sexual harassment in the global work place. The model shows a nation's cultural values and laws are influencing each other, and at the same time both the culture and the laws are influencing the individual citizen's sexual harassment script. The second part of the model deals with the sexual harassment scripts of the individual citizen of a given nation.

\section{The Sexual Harassment Script}

Cognitive psychologists Shank and Abelson (1977) originally described a script as a "structure that describes appropriate sequences of events in a particular context ...

Figure 1. Sexual Harassment in the International Environment: A Perceptual Model

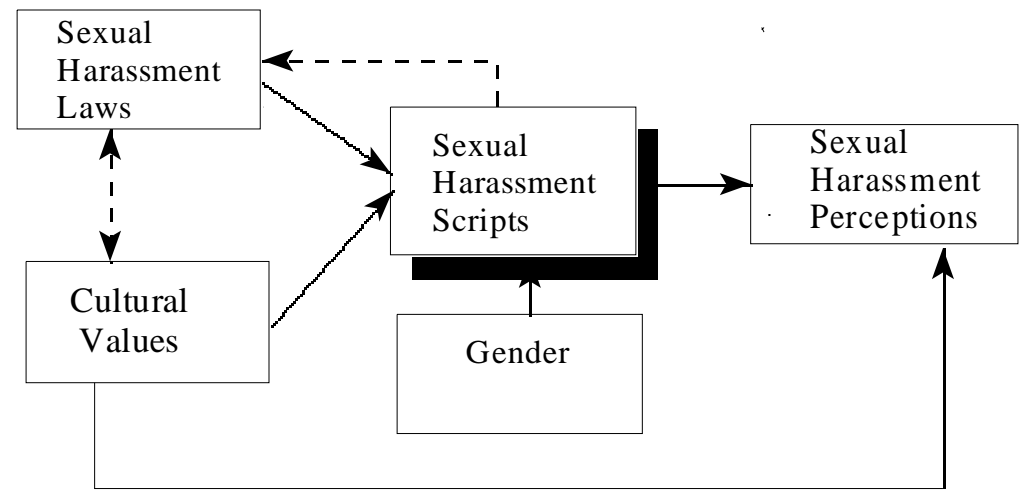

a predetermined stereotyped sequence of actions that defines a well-known situation." The concept of scripts was brought into the organizational behavior setting by Gioia and Poole (1984). Gioia and Poole (1984) applied the concept of scripts to organizational behavior. They believe that the understanding of behavioral scripts will help employees to understand why they and other employees behave as they do and that this understanding will help guide them to choose the best course of action.

Popovich, Jolton, Mastrangelo, Everton, Somers, and Gehlauf (1995) did a study analyzing scripts to study perceptions of sexual harassment. Male and female students were asked to describe a typical workplace sexual harassment incident. Popovich et.al did a content analysis of these incidents and found that there were sex subject differences in what the student considered to be typical harassment behaviors. There 
were also differences between the male and female students regarding motive and victim response.

Based on the studies cited above we propose that the gender of the perceiver will influence the sexual script of the perceiver regardless of their nationality.

$\mathrm{H}_{1}$ - Males will have different perceptions of what behavior constitutes sexual harassment than females regardless of their country of residence.

The cultural influences are very crucial in this aspect as well. To examine this model, perceptions of residents of the United States, Mexico, and Jamaica were gathered. Using Hofstede's (1983) scores, Jamaica, Mexico, and the U.S. show very similar rankings in the Masculinity dimension $(8,6$, and 15 , on a scale of 1 for the highest to 53 the lowest). This is where the similarities end. In the Power Distance dimension the three countries ranked 37 (Jamaica), 6 (Mexico), and 38 (U.S.). In Uncertainty Avoidance they ranked 52,18, and 43, respectively. And in the Individualism Dimension they ranked 25,32 , and 1 , respectively. These scores would suggest that the residents of these three countries perceive and respond to sexual harassment in different ways. We, therefore, propose that the cultural values of that population influence our perceptions or scripts of what constitutes sexual harassment behaviors.

$\mathrm{H}_{2}$ - Residents of the U.S., Jamaica, and Mexico will have different views on sexual harassment in general based differences in their cultures.

The U.S. and Mexico have legal interpretations resulting in rulings against sexual harassment. In Mexico this is traditional sexual harassment where a man harasses a woman. In the U.S. the courts have interpreted this to include traditional harassment as well as non-traditional harassment; i.e., women harassing men as well as same sex harassment. Therefore, we propose that the sexual harassment laws in a given country will influence the perceptions of different types of sexual harassment of the citizens of that country.

$\mathrm{H}_{3 a}$ - Residents of the U.S., Jamaica, and Mexico will not have significantly different views of traditional sexual harassment (male-female).

$\mathrm{H}_{3 \mathrm{~b}}$ - Residents of the U.S., Jamaica, and Mexico will have different views of the three non-traditional types of sexual harassment (Female-Male), (Male-Male), and (Female-Female). 


\section{Methods}

\section{Sample}

Surveys were given to MBA students in the United States, Jamaica, and Mexico. These countries were chosen because Mexico and Jamaica are major trading partners with the United States. In 2001, the United States exported goods valued at $\$ 101.5$ billion to Mexico and \$1, 405.5 million to Jamaica. The U.S. imported \$131.4 billion from Mexico and $\$ 460.6$ million in goods from Jamaica. (STAT-USA, 2002). Also, Mexico and Jamaica have been among the top ten countries that are sources of legal immigration to the United States since 1981. In 2000, 171,748 people legally immigrated to the U.S. from Mexico and 15,654 immigrated from Jamaica (U.S. Department of Justice, 2001). The total of 328 surveys distributed were usable responses, and included 97 from the U.S., 149 from Mexico, and 82 from Jamaica. Of this sample, 147 (44.8\%) respondents were men and 181 (55.2\%) were women. Four individuals did not indicate their gender.

\section{$\underline{\text { Measures }}$}

Fiedler and Hamby (2000) developed the scale used to measure perceptions of sexual harassment 000), which measures the differences in perceptions of sexual harassment among health care professionals. To ensure that this survey would be acceptable in the international environment, it was tested on 33 international students studying in a business administration program. These students were from 13 different countries.

The alpha reliability for the scale in this pilot sample was 0.84 . The scale consisted of six different sexual harassment scenarios, such as "a male supervisor repeatedly tells a female employee that he has sexual dreams about her." Both quid pro quo and hostile environment scenarios were included, and both supervisor and coworker scenarios were given. Each scenario was rephrased four ways to include the non-traditional sexual harassment. For example, based on the above, we also included the following:

- A female supervisor repeatedly tells a male employee that she has sexual dreams about him.

- A male supervisor repeatedly tells a male employee that he has sexual dreams about him.

- A female supervisor repeatedly tells a female employee that he has sexual dreams about her.

There were a total of 24 scenarios given in a scrambled order in the Sexual Harassment Scale (SHS). The SHS included four subscales; that is, the Male-Female Harassment Scale (MFHS), Female-Male Harassment Scale (FMHS), Male-Male Harassment Scale (MMHS), and Female-Female Harassment Scale (FFHS). The MMSH and the FFSH scales were combined to measure perceptions of same sex harassment. The MFSH and the FMSH scales were combined to measure perceptions of opposite sex harassment. The MMSH scale and the MFSH scales were combined to measure 
perceptions of harassment where a male was the perpetrator, and the FMSH scale and the FFSH scales were combined to measure perceptions of harassment where the harassing behavior was demonstrated by a woman. Each scenario was rated on a four point scale with "1" defined as "severe sexual harassment" and "4" define as "not sexual harassment".

Demographic questions included age, gender, and years of managerial experience.

\section{Results}

Alpha reliabilities were run for the main scale and the subscales with the following results: the Sexual Harassment Scale was 0.92, the Male-Female Scale was 0.73, the Female-Male Scale was 0.72, the Male-Male Scale was 0.72, and the Female-Female Scale was 0.72 . Between group differences based on gender were examined using ttests. The between group differences based on country of residence as well as the interaction effect between the country and the gender were examined using an ANOVA and a MANOVA. Descriptive statistics, including means and standard deviations were also included.

\section{Perception Based on Gender Differences}

To determine whether men and women carried different sexual harassment scripts, $t$ tests were used to measure differences between men and women on perceptions of overall sexual harassment. Table 1 shows that for the entire sample there is a significant difference between men and women in their perceptions of sexual harassment. However, when the sample was broken down by countries it was found

Table 1. Perceptions Based on Gender

\begin{tabular}{llllll}
\hline & Gender & $\mathrm{N}$ & Mean & s.d. & $P$ \\
\hline Male-Female & Male & 147 & 12.4 & 3.91 & .042 \\
& Female & 181 & 11.55 & 3.6 & \\
Female-Male & Male & 147 & 13.84 & 3.8 & .000 \\
& Female & 181 & 12.3 & 3.72 & \\
Male-Male & Male & 147 & 11.87 & 4.16 & .300 \\
& Female & 181 & 11.42 & 3.59 & \\
Female-Female & Male & 147 & 12.91 & 3.8 & .015 \\
& Female & 181 & 11.87 & 3.87 & \\
Total & & & & & \\
Harassment & Male & 147 & 51.02 & 13.82 & .011 \\
& Female & 181 & 47.14 & 13.55 & \\
& & & & &
\end{tabular}


that while there were significant differences in the perceptions of men and women in Mexico $(p<.03)$, there was no significant difference in the perceptions of men and women from the United States or Jamaica ( $p<.171$ and $p<.640$, respectively).

Therefore, hypothesis two was partially supported. It is interesting to note that the means for both the men and the women in the U.S. were below the mean for the whole group thus indicating that in the U.S. both genders are more sensitive to harassment issues, while the mean scores for both the men and the women in Jamaica are below the mean of the group as a whole.

\section{Perceptions Based on Culture}

An ANOVA was used to determine whether there was an overall difference on perceptions of sexual harassment based on country of residence. Because of the significant correlation between gender and sexual harassment perceptions, gender was used as a covariate. See Table 2. Hypothesis 2 was supported. There were significant difference between the three countries $(p<.012)$.

Table 2. Perceptions of Sexual Harassment by Country, Univariate Analysis of Variance With Gender as a Covariate

\begin{tabular}{lccc}
\hline $\begin{array}{l}\text { Source of } \\
\text { Variance }\end{array}$ & $\begin{array}{c}\text { Univariate } \\
\text { F-Ratio }\end{array}$ & $\begin{array}{c}\text { Degrees of } \\
\text { Freedom }\end{array}$ & P Less Than \\
\hline Country $(c)$ & 5.694 & 1 & 0.018 \\
Gender $(g)$ & 4.494 & 2 & 0.012 \\
\hline
\end{tabular}

\section{Perceptions Based on the Laws}

Table 3 shows that there is a significant difference between countries on two types of sexual harassment, male-female $(p<.001)$ and female-male $(p<.001)$. Bonferroni tests indicate there are significant differences on these variables between each of these countries. This only partially supports hypothesis $3 a$. There is no significant difference between countries on same-sex harassment, male-male $(p<.637)$ and female-female (p.<.435). This does not support hypothesis $3 \mathrm{~b}$. Bonferroni tests indicate there are no significant differences on these variables between any of these countries. This would seem to indicate that culture has a greater impact on the perceptions of sexual harassment than the laws.

\section{Discussion}

The results of the study show that Hofstede's cultural dimensions can be used to predict certain dominant organizational behaviors. However, the observer must be careful not to evaluate the countries on the basis of a single dimension, because the most important issue is the interaction between them. It is possible that a single dimension may become the dominant determinant of certain behavioral characteristics of a culture, 
but these are not common situations. The three countries in the study (Jamaica, Mexico and the U.S.), have shown relatively high scores on the Masculinity dimension. This means that the three countries' dominant values are assertiveness, success, money, etc. This would indicate that these cultures place less importance on the Feminine values such as personal relationships, care for others, etc. But, Mexico shows higher levels of Machismo than the other two, which also goes along with the paternalistic style of leadership and management. The results of this research support the prediction that women and men would have different perceptions of sexual harassment in Mexico, but not in Jamaica or the United States.

Examining the other cultural dimensions, Mexico is the country that shows the strongest level of Uncertainty Avoidance among the three. Also Mexico has the highest score in Power Distance of the three countries. This would indicate, for instance, that Mexicans tend to prefer structured situations, and that they expect the structure and the rules to be determine by those in position of authority. Thus women in Mexico, even if they possess different perceptions of sexual harassment, are less likely to initiate changes to enact laws or rules to protect them. Both in Jamaica and in the U.S. (Weak Uncertainty Avoidance and low Power Distance), would indicate that the women in these countries would be expected to even take the initiative to impose their views and actions to protect themselves against any unwanted behavior. These predictions were supported by the results of this study.

The last cultural dimension discussed is Individualism. The U.S. is probably the country with the highest level of individuality among all countries around the world, with both Jamaica and Mexico and Jamaica showing low levels of individuality. What this suggests is that people in the U.S. would tend to stand for themselves more than people in either Mexico or Jamaica. Mexicans and Jamaicans are more likely to value the overall good of the group, and they would subordinate their own individual interests and needs for the benefit of the group. Loyalty and group harmony become very important. Thus women in Mexico and Jamaica may be less likely to complain about coworkers' unwanted behaviors than women in the United States. Finally, it is also important to observe that Mexican and Jamaican males are less likely to report harassment by women than males in the United States. The combination of cultural attributes in Mexico and Jamaica would make males feel embarrassed if they were to complain of sexual harassment by female coworkers in the workplace. Society in these two countries expects men to handle these situations in other ways.

Finally, although not an objective pursued by this study, it could be said that the legal apparatus and implications of sexual harassment in these three countries differ to some extend by the culture. Which laws are enacted and how they are enforced could be determined at least in part by the specifics of the culture of each country.

\section{Conclusions}

Today's organizations cannot afford to ignore the potential for conflicts between employees who come from different cultural backgrounds. These conflicts can vary from 
the funny situations to very serious ones, such as sexual harassment. The probability for an employee working with or dealing directly with a customer, or a supplier from a totally different culture is very high. A typical situation could be when an employee from a cultural without particular laws covering sexual harassment, for example Jamaica, comes to a country such as the U.S., where sexual harassment has been codified and strongly upheld by the courts. The behavior of this unsuspecting Jamaican employee in the U.S. may not only cause his or her company some embarrassment, but under the Civil Rights Act of 1991 and many state laws, it could cause the organization to be subject to fines sometimes in excess of U.S. \$1 million. In addition to the potential financial consequences, there might be some more serious problems associated with public support, acceptance of the company's products or services, etc.

While this model was tested using data from the U.S., Mexico, and Jamaica, it is highly possible that these types of difference would be found between other countries such as the Northern European and the Southern European countries. All organizations should operate today under the understanding that, once they become engaged in the global village, they are not just global or multinational companies. They are also multicultural organizations, and as such they also become multi-legal to be able to operate within the framework of the legal systems of the various countries where they operate. This notion can be extended to say that these firms also become multi-social because the social context varies according to the specific cultural environment. Again, it can be speculated that the techniques and basic concepts in management in general, and in HRM in particular, are similar all over the world, but it is the legal, cultural and social context that defines the way these tools and concepts are applied.

The results of the present study and the new realities of the global village demand now that we shift emphasis away from the comparative approaches used today in most of the international management studies and programs (e.g., Hofstede, 1980, 1983), and begin concentrating more on integrative efforts (e.g., Koopman, 1994). Through crosscultural training, we find ways to develop and maintain synergies that would allow firms to become more competitive in the global market. There is no doubt that global and multinational firms, and even others that may not be globalized but are engaged in some way in global business, might face many of the cross-cultural encounters mentioned above through their interaction with foreign labor, or suppliers, or customers. Exposure to the different cultures, which should include the understanding and acceptance of the uniqueness of each culture, becomes a primary need. There is an increased need for an understanding of behaviors, legal environment, social context, educational systems, etc., which exist in the countries in which modern organizations operate. The final outcome of this effort should be the development of not only a pluralistic organization, but also one with a multicultural workforce from the top ranks all the way to lowest ranks.

Future studies should examine outcomes of these perceptions in various countries. Behaviors such as filing complaints with managers as well as the government should be examined. Also the study should be expanded to include European and Asian countries. 


\section{References}

Ashforth, B. \& Fried, Y. (1988). The Mindlessness of Organizational Behaviors. Human Relations, 41(4), 305-330.

Baird, C.L., Bensko, N.L., Bell, P.A., Viney, W., \& Woody, W.D. (1995). Gender Influence on Perceptions of Hostile Environment Sexual Harassment. Psychological Reports, 77, 79-82.

Barnum, C. (1991). Effective Membership in The Global Business Community. In J. Renessch (ed.), The New Traditions in Business. San Francisco: Sterling \& Stone.

Blanco, R. I. (1995). "Expatriate Support Systems," A Definition. In L. Peters, S. Youngblood, \& C. Greer (eds.), A Dictionary of Human Resource Management. Cambridge: Blackwell.

BNA International Business and Finance Daily (March 29, 1994), The Bureau of National Affairs, Inc.

Bried, A. and Hayes, E. (1997). The Continuing "American Dilemma": Studying Racism in Organizations. Journal of Organizational Behavior, 4, 89-105.

Bureau of Democracy, Human Rights, and Labor a (2000). 1999 Country Reports on Human Rights Practices: Jamaica. Released by the Bureau of Democracy, Human Rights, and Labor U.S. Department of State, February 25, 2000.

Bureau of Democracy, Human Rights, and Labor a (2005). 2004 Country Reports on Human Rights Practices: Jamaica. Released by the Bureau of Democracy, Human Rights, and Labor U.S. Department of State, February 28, 2005.

Bureau of Democracy, Human Rights, and Labor $b$ (2000). 1999 Country Reports on Human Rights Practices: Mexico. Released by the Bureau of Democracy, Human Rights, and Labor U.S. Department of State, February 25, 2000.

Bureau of Democracy, Human Rights, and Labor $b$ (2005). 2004 Country Reports on Human Rights Practices: Mexico. Released by the Bureau of Democracy, Human Rights, and Labor U.S. Department of State, February 28, 2005.

Dietz-Uhler, B. and Murrell, A. (1992). College Students Perceptions of Sexual Harassment: Are Gender Differences Decreasing? Journal of College Student Development, 33, 540-546.

Duncan, L. (November 5, 1993). A Try for Laughs Pays to Tough Crowds. Chicago Daily Law Bulletin. 
The Economist (October 3, 1994). Economist Intelligence Unit Business-Europe.

Englander, J. (1992). Handling Sexual Harassment In The Workplace. The CPA Journal, 62, 14.

Fiedler, A. \& Hamby. E. (2000) Sexual Harassment in Healthcare: Nurses' Perceptions. Journal of Nursing Administration, 30(10):497-503.

Gershenberg, I. (1994). Gender, Training, and the Creation of the Managerial Elite: Multinationals and Other Firms in Jamaica. The Journal of Developing Areas, 28, 313324.

Gioia, D. A., \& Poole, P. (1984). Scripts in Organizational Behavior. Academy of Management Review, 9, 449-459.

Gordon, G. (1991). A Worldwide Look at Sexual Harassment. IABC Communication World, 12, 15- 19.

Grant, L. (June 12, 1995). Mexican Machismo and Working Women. The San Francisco Examiner.

Gutek, B. A., Morasch, B., \& Cohen, A.G. (1983). Interpreting Social-Sexual Behavior in a Work Setting. Journal of Vocational Behavior, 22, 30-48.

Hofstede, G. (1983). Dimensions of National Culture in Fifty Countries and Three Regions, in J.B. Deregowski, S.Dziurawiec, and R.C. Annios (eds.). Expectations in Cross-Cultural Psychology, Swets and Zeitlinger, Lisse, Netherlands, 335-355.

Hofstede, G. (1984). Culture's Consequences: International Differences in WorkRelated Values. London, UK: SAGE Publications, Ltd.

Ioannou, L. (1995). Capitalizing on Global Surplus Labor. International Business, April, 32-41.

Koopman, A. (1994). Transcultural Management: How to Unlock Global Resources. Oxford. UK: Blackwell Publishers.

National Catholic Reporter (May 20, 1994).

Padgitt, S.C., \& Padgitt, J.S. (1986). Cognitive Structure of Sexual Harassment. Journal of College Student Personnel, 34-39.

Popovich, P.M., Gehlauf, D.N., Jolton, J.A., Somers, J.M., \& Godinho, R.M. (1992). Perceptions of Sexual Harassment as a Function of Sex of Rater and Incident Form and Consequence, Sex Roles, 27, 609-625. 
Popovich, P.M., Jolton, J.A., Mastrangelo, P.M., Everton, W.J., Somers, J.M. \& Gehlauf, D.N. (1995). Sexual Harassment Scripts: A Means to Understanding a Phenomenon. Sex Roles, 32(5/6), 315-335.

Rhinesmith, S. H. (1993). A Manager's Guide to Globalization: Six Keys to Success in a Changing World. Homewood, IL: Richard D. Irwin, Inc.

Riding, A. (November 3, 1992). Harassment or Flirting? Europe Tries to Decide. The New York Times, A8.

Rueters News Service (2002). http://sg.news.yahoo.com/reuters April 19, 4:07 AM

Shimbun, Y. (February 10, 1994). Video Warns Against Sexual Harassment Abroad. The Daily Yomiuri.

STAT-USA (June 2002). http//www.stat-usa-gov/tradtest.nsf.

Sullivan, F.L. (1986). Sexual harassment: The Supreme Court Ruling. Personnel, 65(12), 42-44.

Tomlinson, O. (April 20, 2004). Bureau of Women's Affairs Wants Anti-Sexual Harrassment Law http://www.jis.gov.jm/development/html.

United Nations Statistics Division (2000) The World's Women 2000: Trends and Statistics, United Nations.

U.S. Department of Justice (2001). Immigrants, Fiscal Year 2000. 2000 Statistical Yearbook of the Immigration and Naturalization Service.

U.S. Department of State (December 27, 1993). Disability, language or social status.

Vitell, S., Nwachakwu, \& Barnes, J. (1993). The Effects of Culture on Ethical Decisionmaking: An Application of Hofstede's Typology. Journal of Business Ethics, 12, 753760.

Vogel, D. (1993). Is U.S. Business Obsessed with Ethics? Across the Board, 30(9), 30.

WQED/Pittsburgh (1994). In association with The Carden Company, produced "Between Two Countries: Japan in America." 